Families in Society: The Journal of Contemporary Human Services

Copyright 1995 Families International, Inc.

CEU Article No. 56

\title{
Service System Barriers to Reunification
}

\author{
Christopher G. Petr $E 3$ Cindy Entriken
}

\begin{abstract}
Programs to reunite children in state custody with their families and communities have not proliferated to the same extent as have programs designed to prevent placement. Although reunification is generally recognized as a more complex and formidable undertaking, the nature and extent of the obstacles to reunification are not fully understood. The authors report on five major systems barriers to reunification that were identified through a pilot case management project in a midwestern state. Knowledge of these obstacles can help officials create a context in which reunification programs have optimal opportunity to succeed.
\end{abstract}

F amily reunification following out-of-

F home placement of children has long been a focus of social work practice in child welfare. Reunification is important because a child's development and well-being are believed to be best enhanced through a continuous caretaking relationship provided by biological parents, because the child in foster care might suffer permanent psychological damage as a result of disruption in the parent-child attachment, and because foster care is costly to the state (George, 1990). Family reunification is also an important part of a general policy initiative in the social services field directed toward supporting children in their own homes and thus reversing past overreliance on out-ofhome care (Petr \& Spano, 1990).

Federal permanency planning legislation in 1980 provided an opportunity for renewed emphasis on reunification. The Adoption Assistance and Child Welfare Act of 1980 (P.L. 96-272) required states to make reasonable efforts to prevent the out-of-home placement of abused and neglected children. If a child must be placed into custody, the law requires states to make reasonable efforts for the child to return home. Although P.L. 96-272 emphasizes both prevention of placement and reunification, subsequent child-welfare programming and research have emphasized prevention of placement through home-based family preservation programs (Wells \& Biegel, 1991; Whitaker, Kinney, Tracy, \& Booth, 1990). Meanwhile, reunification efforts generally have taken place as part of the regular foster care services offered by state agencies, rather than as specific programs (Fein \& Staff, 1993).

Because of this relative lack of emphasis, the knowledge base for reunification practice is not as developed as that for family preservation (Frankel, 1988). The little outcomebased research on reunification that has been

Christopher G. Petr is Associate Professor, School of Social Welfare, University of Kansas, Lawrence, Kansas. Cindy Entriken is Executive Director, Sedgwick County Area Community Housing Organization, Wichita, Kansas, and a doctoral student at the School of Social Welfare, University of Kansas. This article is based on work funded by the Annie E. Casey Foundation, Kansas Department of Social and Rehabilitation Services, and the National Institute of Disabilities and Rehabilitation Research grant H133B80046. 
done has yielded mixed results. Lahti (1982) reported findings from a comparison group study of programmatic efforts to secure permanent placements for 259 children in foster care, either by reuniting them with their families of origin or by placing them with adoptive families. Project efforts resulted in significantly more children being placed in adoption than occurred in the comparison group, but no significant differences were found between groups in the number of children returning to parents. This result was confounded, however, by differences between the project-and comparison-group selection procedures. The project group was selected from a pool in which caseworkers considered family reunification to be unlikely, whereas the comparison group did not have this restriction. Fein and Staff (1993) studied 68 primarily preschool-aged abused and neglected children who received reunification services for at least six months. Of these, $26(38 \%)$ were reunified, but 7 returned to foster care. Thus, $28 \%$ of the families remained reunified by the end of the second year of the program. In a control group study of reunification, Walton, Fraser, Lewis, Pecora, and Walton (1993) reported that after a 90 -day service period, $93 \%$ of the treatment group compared with $28 \%$ in the control group were reunited. Twelve months after treatment, $75 \%$ of the treatment children were in their homes compared with $49 \%$ of the control children.

The relative inattention to reunification may be due, in part, to the greater complexity and difficulty inherent in attempting to reunite children with their families compared with preventing placement (Allen, 1992). During placement, various new persons and systems typically become involved with the child, including the court, attorneys, out-of-home care providers, foster-care workers, new school personnel, and therapists. The child and family may feel relief at the placement and may be ambivalent about reintegration (Hess \& Folaron, 1991). Teaching and learning parenting skills may be more challenging when the child is not in the home, and families may have to overcome a sense of failure and incompetence (Krieger, Maluccio, \& Pine, 1991). In addition, the longer the child is in placement the more difficult it is to achieve successful reunification (George, 1990).

Like all social programs, reunification efforts are constrained by agency, policy, and program contexts. To date, no study of reunification has illuminated these constraints. Clear identification and analysis of the attitudes, policies, and practices that inhibit and impede reunification efforts at the direct-practice level could help policymakers design more effective reunification initiatives.

The present study was developed as part of a midwestern state's efforts to improve the health and welfare of children in the state. The overall purpose of the project was to explore factors for achieving successful reunification. The premise of the project was that successful reunification efforts at a direct-practice level require lighter case loads, intensive training and supervision, and a model that is family centered and strengths focused.

Recognizing that successful direct practice is highly dependent upon a supportive policy and program context, particularly in the complex arena of reunification, one of the project's goals was to identify systematically the servicesystem barriers that impeded and blocked reunification efforts. These systems barriers were identified through the initiation of reunification case management services for 20 randomly selected children in state custody. Thus, the direct experiences of these case managers, working to overcome service-system barriers encountered with these 20 youth, provided the raw data for the study.

\section{Methodology \\ Definition of Reunification}

The aim and focus of reunification is twofold, centering on both the family and the community. One purpose is "to help the child and family to achieve, at any given time, their optimal level of reconnection-from full reentry into the family system to other forms of contact and affirmation of the child's membership in that family, such as visiting" (Krieger et al., 1991, p. 2). When the child is placed outside the community of origin, a second purpose is to reconnect the child with the community, which, together with the family, shares respon- 
sibility for the growth and nurturance of each of its young citizens.

For the purposes of this project, reunification was defined as follows: Reunification is the planned process of achieving permanent placements for children with:

- Their families (reintegration), or

- A permanent family-like setting with optimal emotional reconnection with the family when reintegration with their own family is not possible, or

- Independent living with optimal emotional reconnection with their family, when the age and situation of the youth make independent living the most appropriate goal, and

- Their community of family origin

This definition draws an important distinction between the terms reunification and reintegration. Reintegration refers to the physical reintegration of children with their families. Reunification is a more encompassing term that includes reintegration as one component. Thus, this definition views reunification on a continuum, not dichotomously. Return to the community and emotional reconnection are important reunification goals regardless whether the permanency-planning goal is reintegration, adoption, independent living, or long-term placement. Thus, even when physical reintegration with the family is not the permanency-planning goal, the child can still be returned to the community of origin, and the child and family can attain some measure of emotional reconnection.

\section{Sample}

Researchers and state officials agreed to study the reunification issues for children in state custody from the state's most urban and populous county who were placed in the most expensive, restrictive settings. This included group homes, youth correctional facilities, and institutions, but excluded family foster care. This target population was chosen because youth in these placements posed the greatest reunification challenges for foster-care workers and they cost the most for the state to maintain in placement. Thus, it was believed that the state could get the "most mileage" from learning about the reunification barriers for this group.
The sampling pool included two broad categories of youth-children in need of care and juvenile offenders. Children in need of care are abused or neglected or behaviorally troubled children such as truants and runaways. Juvenile offenders have committed criminal offenses. This mix was potentially problematic because these two groups of youth often are thought of as distinct populations with disparate characteristics and needs and because the case-planning requirements and other provisions of P.L. 96-272 do not automatically apply to juvenile offenders. Consideration was given to narrowing the target population to children in need of care only, but the decision was made to include juvenile offenders based on several important considerations. First, the number of juvenile offenders from the county placed in restrictive, expensive settings outnumbered children in need of care. Of the 410 children from the county placed in expensive, restrictive settings, 242 (59\%) were juvenile offenders. Exclusion of juvenile offenders would have meant exclusion of the majority of children in the population of concern. Second, state policy required that both juvenile offenders and children in need of care in state custody be subject to the same case-planning requirements of P.L. 96 272. This policy applied even to juvenile offenders placed at correction and detention facilities, in that their length of stay could not be predetermined by court sentencing. Third, awareness of the reunification needs of juvenile offenders and their families is growing (Gordon, Arbuthnot, Gustafson, \& McGreen, 1988; Kagan, Reid, Roberts, \& Silverman-Pollow, 1987), as is the related notion that these needs may not differ significantly from children in need of care.

A random sample of 20 children was selected. Random sampling was employed to represent most accurately the entire target population and to ensure that barriers to reunification identified for the sample group could be reasonably generalized to the target population as a whole. Of the 20 randomly selected children, six were children in need of care and 14 were juvenile offenders, 15 were male and 5 female, 11 were white and 9 were nonwhite. The mean number of months in 
state custody was 20.5 (range 4 to 102 ); the mean number of prior placements while in custody was 5.9 (range 2 to 31). The average age was 15.1 years (range 12 to 17 ).

\section{Procedure}

Children in this group received reunification case management services under a contract between the state child-welfare department and a local agency. From April 1, 1992, to March 31, 1993, two bachelor's-level case managers provided reunification services to the 20 randomly selected children. One was a white male, the other an African American female. Each had a case load of 10 , which they followed for the entire year of the project.

Case management in this project involved helping the family and child obtain the services and resources necessary to achieve their reunification goals. An initial three-day training program and later supervision sessions were guided by materials on a strengths approach to case management (Poertner $\&$ Ronnau, 1992) and by a reunification sourcebook (Krieger et al., 1991). The case management intervention emphasized (1) establishing clear reunification goals and contracts with the child and family, (2) identifying and building on strengths of the child and family, (3) assertive problem solving, and (4) the building of community-service teams for each case. Weekly supervision of case managers was provided by the second author. Supervision meetings were also attended by staff from the local children's planning council and state childwelfare supervisory personnel who provided consultation regarding state and community resources. Case managers had access to limited "flexible funds" to meet some family and child needs. (See the project's final report [Petr \& Entriken, 1993] for a complete description of the case management efforts, including analysis of outcomes.)

Two procedures were used to identify barriers to reunification. At the beginning of the project, staff conducted a review of each youth's official case plans with respect to reunification efforts. This review assessed clarity of reunification goals, involvement and participation by families, including visitation, efforts to address the child's needs and behaviors, and efforts to arrange needed community services. As the reunification efforts progressed, researchers systematically collected information about the obstacles and barriers encountered by the case managers. Each week during group supervision sessions, case managers reported the problems confronting them in the service system when they attempted to arrange family visits, set up case staffings, acquire needed resources, and otherwise pursue reunification goals. Research staff maintained a written record of these specific systems barriers and, after eight months of service, classified them into five categories. A special subcommittee of the local planning council composed of agency administrators, service providers, and citizens worked with the staff in classifying and overcoming the identified barriers, both at the individual and systems levels. Because this was a random sample, the barriers experienced by the group were deemed reasonably representative of the larger target population.

\section{Results: Five Major Barriers}

Overall, the systems barriers were wide ranging and acted as prohibitive obstacles to the case managers' efforts. Even with light case loads and extra training and supervision, the staff spent valuable time and energy attempting to overcome these obstacles. Essentially, the reunification case managers were charged with mobilizing an entire system of care whose programs and policies were antithetical to reunification. Reunification efforts are impeded when the larger system (1) pays little attention to reunification goals, (2) places youth far from their families and communities, (3) allows the mission and policies of youth corrections to focus only on rehabilitation of the youth, (4) lacks a community-based system of services, and (5) fails to involve families in respectful, collaborative ways.

\section{Lack of Attention to Reunification Goals and Principles}

Project case managers confronted a system of care that focused on treatment and care for the child, with little focus or priority on family and reunification. Reunification was not the driving force of service delivery. This 


\section{Barriers to Reunification \\ Petr E Entriken}

inattention to reunification was reflected in the official case plans, which case managers and research staff reviewed at the onset of the project. In 14 of the 20 case plans, no mention was made of tasks and services needed for the family to resolve problems that led to placement. Only 4 of 20 case plans addressed family visitation or other emotional reconnection strategies in specific terms. In 14 cases the plan did not focus attention on arranging community resources and services, such as education and mental health. So severe was this inattention to community resources that seven children were abruptly returned to their families before the case manager could build a community support system. In contrast with this inattention to family and community, 14 plans identified a services plan for the youth, including tasks to resolve problems that precipitated placement. The system of care seemed content to focus its efforts on the care of the child, with little pressure, incentive, or accountability toward reunification.

When professionals in the system did address reunification, they thought almost exclusively in terms of reintegration. If family reintegration was not the goal, then community reintegration and emotional reconnection with the family were not deemed important. For example, one of the youth in the project was age 17 and residing at a group home when the project started. He had been placed in state custody at age eight after severe physical and sexual abuse by the parents, and shortly afterward parental rights were severed for him and his two siblings. The boy had stayed in state custody ever since, in nine different placements, and had rarely seen his siblings. Responding to his requests to reestablish contact with his siblings, the case manager discovered one adult brother living in a nearby city who became an active resource. The brother supported plans for independent living in his small community and helped arrange community-support services.

\section{Geographic Distance}

Distance, in and of itself, was a formidable barrier to reunification. Fifteen of the 20 youth were placed outside the county in various parts of the state. As our case managers discovered, distance impeded reunification in several ways. First, it made it much more difficult for the local foster-care worker to know the child and to monitor implementation of the case plan. Roles and responsibilities between the local foster-care worker and the staff of the placement facility were confused and conflicted. As a result, it was often difficult to clarify who was in charge of organizing and coordinating reunification efforts. Second, geographic distance meant that a worker had to commit valuable time to travel, which affected the worker's overall efficiency. A worker visit to one child could easily constitute a full day's work. Third, distance was a strong barrier to family visitation and involvement. Poor families lack transportation resources, and working families struggle to find the time. Fourth, distance impeded the formation of communitybased supports and services on behalf of a child. Even if a time and place could be arranged, it was difficult for community professionals to meet to coordinate services for a child whom they did not know and whom they felt little obligation to serve without the child first establishing physical residency in the community.

\section{Policies of Youth Correctional Facilities}

Laws and policies in the state had long promoted an orientation toward juvenile offenders that emphasized punishment and rehabilitation of the offenders themselves. It was not altogether surprising, then, to find that reunification with family and community was not emphasized by staff and programs of the youth correctional facilities. Project case managers encountered many obstacles to family visits, phone calls, and family involvement in treatment planning. These obstacles ranged from treating visits and phone calls as earned privileges to failure to involve parents in discharge planning. Many staff stereotyped parents as hostile, resistant, and uncaring and refused to change their attitude even after case managers had forged good working relationships with the parents. Planning for community-based services prior to discharge was almost nonexistent prior to our efforts.

These barriers strongly affected the work of the case managers. Ten of the 20 youth were 
Families in Society

November 1995

residing at youth correctional facilities at the onset of the project. Despite the case managers' efforts to achieve reunification goals, two youth in the project spent the entire project year at a youth facility and another stayed for 343 days of the year. Six other youth were abruptly discharged back to the community without family or community services in place prior to return.

\section{Lack of Community-Based Programs and Coordination}

Case managers found that the community lacked effective and coordinated programs to deal with this population. First, the community needed nontraditional educational programming that combined some classroom work with jobs and earning money. Second, linkages were needed between placement facilities and community programs, especially in the educational and mental health systems. In education, delays in sending educational records resulted in delays in enrollment. All 20 children met the state department of mental health's definition of seriously emotionally disturbed, yet few of the youth were able to access community mental health services. Third, the problem of sexual abuse was not addressed in a comprehensive, programmatic way. Despite the increase in children who are abused in the community ( 6 of 20 in the project group) and despite the fact that other metropolitan communities in the state had developed comprehensive, interagency programs, the county in this study did not have such a program.

\section{Barriers to Family Involvement}

We encountered widespread negative stereotyping of families as dysfunctional, unmotivated, and uncaring. Contrary to this stereotype, the families in our study expressed strong interest in their children and for the most part cooperated with our efforts. Initially some of the parents were less than enthusiastic, but case managers were generally successful in overcoming their initial resistance and hostility. The training and supervision emphasized a family-centered approach that involved communicating respect for parents, listening to and addressing their concerns, focusing on strengths, and helping them stay emotionally connected to their children through visits and phone calls.

Although parents typically had some anxiety and understandable ambivalence about reunification and sometimes disagreement about the specific course of action, all of the parents expressed concern and care toward their children. This is not to say that families were problem free, but our experience indicated that when families were approached in a collaborative, strengths-focused way, they could be engaged in a productive, problem-solving process. Prior to the case-manager involvement, parents were rarely involved in their child's life, not because they didn't want to be, but because the professionals and policies overtly discouraged their involvement. For example, parents often were not notified of staffings and administrative reviews, and contacts through visits and phone calls were often viewed as a privilege to be earned by the child, rather than as a right.

Part of the tension between parents and professionals may be related to disagreements about the level, or standard, of family functioning required for reintegration. The larger community, including judges, teachers, and other professionals, may have higher expectations of families than do child-welfare workers, children, and families themselves. The issue appears to revolve around how much risk one is willing to take. Being overly cautious may lead to children spending excessive time in state custody, but taking too great a risk may expose children to abuse and neglect, or expose the community to unlawful acts. Objective, empirical data about this risk issue is lacking, as risk-assessment research has not focused on reintegration as the point in time for assessing risk (McDonald \& Marks, 1991).

\section{Overcoming Barriers to Reunification}

Through the previously mentioned subcommittee of the local children's planning council, local and state officials worked together to overcome the systems barriers. Progress occurred on several fronts. Meetings were held with superintendents of youth correctional facilities and other state officials, re- 
sulting in several changes in policy, including liberalization of family contacts, endorsement of the principle that family contact would not be contingent on the youth's behavior, and formation of a parent advisory group. State policy changed to require that initial reunification plans be written within 30 working days of the child's removal, a dramatic improvement over the requirements of statute and previous policy. The local committee began an inventory of placement resources within the county with the goal of discontinuing the practice of sending youth in state custody outside the community. At the state level, officials moved toward implementation of a regional placement policy in which youth would be placed within a 75 -mile radius of their community. A state-level children's planning group became a partner in a project to measure and improve the level of family-centered professional practice.

Reasonable efforts to reunite children with their families, required by P.L. 96-272, must include attention to the policy and service system context in which direct reunification services are provided. The barriers uncovered in this project apply directly only to the county, state, and target population studied, so caution must be maintained in generalizing results to other states. Nevertheless, our experiences do suggest several target issues for states to assess and evaluate in developing reunification initiatives, especially those targeted at youth placed in expensive, restrictive environments. The thrust of these recommendations is to make reunification the driving force of service delivery for children in state custody.

\section{Keep Kids in Their Community}

The distance barrier to reunification can be rendered moot by establishing firm policies and the necessary placement resources to place youth within their own neighborhoods and communities when family preservation efforts are not successful. This allows the child to maintain stability and continuity with family, school, peer, and community involvement. It enhances the child's sense of belonging and underscores the community's role and responsibility in the care and upbringing of children.
Realization of this goal involves consideration of "no reject" and "no eject" policies for local youth by local foster homes and group homes and aggressive pursuit of neighborhood and kinship placement resources. It also means addressing fiscal incentives or disincentives to out-of-community placement, such as educational dollars following the child. Innovative demonstration programs in this arena have recently been initiated in six states by the Annie E. Casey Foundation's (1992) Family to Family Initiative.

\section{Promote Family-Centered Professional Practice}

Professional insensitivity to families crosses many disciplines, as has been documented from the perspective of families in the fields of mental health, child welfare, and special education (Diorio, 1992; Friesen \& Koroloff, 1990; Petr \& Barney, 1993; Tarico, Low, Trupin, \& Forsyth-Stephens, 1989; Turnbull \& Turnbull, 1985). This study of reunification provides further support for the importance of family-centered practice. Viewed from a value perspective, family centeredness is an important end in itself; viewed from a pragmatic perspective, it may well be necessary to the achievement of successful outcomes.

In general, family-centered practice involves viewing the family as the primary unit of attention and providing services in a collaborative manner in accordance with family wishes, strengths, and needs. In the reunification arena, this translates into practices such as not blaming families, aggressively seeking kinship placements, fully informing and involving families in all major decisions affecting the child's care, and actively supporting family visitation based on the notion that family connection is a right, not an earned privilege. Family-centered practice means providing the formal and informal community services that support family attempts to care for children, including the willingness of professionals to consider taking greater risks.

This recommendation can be achieved through two related strategies. The first strategy is to influence professional attitudes by means of education and training programs. This starts in higher education, where new 
professionals adopt values, attitudes, and philosophies that continue into their profes. sional practice. Courses in professional-parent collaboration are now required in many special-education programs, providing a model for social work, psychology, and other disciplines (Turnbull \& Turnbull, 1990). Training programs on collaboration targeted at current practitioners are also necessary. The second strategy involves empowering parents themselves to effect change in the system by supporting the formation of parent-advocacy organizations. These organizations can provide advocacy to individual parents at the case level as well as advocate for change at the local, state, and national policy level.

\section{Provide Training and Incentives for Reunification Planning}

Reunification is by definition a planned process. Competency-based training in reunification should be required of all foster-care workers. Beyond that, workers must be provided with reasonable case loads and clear incentives to ensure that reunification plans are written in a timely fashion and are reviewed and revised frequently. Reunification planning should begin immediately after a child is placed into state custody, and most plans should be reviewed more frequently than the minimum standard of six months set forth in P.L. 96-272. Traditional ways to achieve these goals include setting out requirements in law or policy and basing performance evaluations on these requirements. Putting requirements into law affords the opportunity for persons outside the child-welfare department to participate in accountability through the legal system and thus promotes a wider sense of community responsibility for children in care. Another promising method of monitoring reunification and developing this sense of community responsibility is citizen review, in which citizens from the community act as a review board for children in state custody (Jennings \& McDonald, 1993).

\section{Reform the System of Care for Juvenile Offenders}

This project brought attention to the reunification needs for juvenile offenders in state custody. The concepts of permanency planning, prevention of placement, and reunification, established in law by P.L. $96-272$ for children in foster care, do not necessarily encompass juvenile offenders in state custody. Even though the characteristics of the two populations may be different, both share the goal to live with families in nurturing communities. In determining to make reunification the driving force of service delivery, states would serve their interests by reviewing the mission, philosophy, and outcomes of their juvenile-justice programs, with particular attention to programs that successfully emphasize the role of family and community in the rehabilitation of youth and protection of the community (Schwartz, 1992). For example, parental visiting has been shown to have a direct beneficial effect upon the behavior of children in correctional placements (Borgman, 1985).

\section{Ensure That Community-Based Programs Are Available and Coordinated}

The reunification needs of children in care, be they abused and neglected, juvenile offenders, or children with emotional disorders, cross many different service systems. Overreliance on categorical and institutional services inhibits the development of coordinated, flexible, and individualized responses in the community. Promising initiatives in this arena include decategorized funding strategies that promote reinvestment of scarce state resources from institutional to community-based care (Bruner, 1989; Deiker, 1986; Rapp \& Moore, 1993).

\section{Conclusion}

The central lesson to be learned from this project is that allocation of resources to the casework practice level may not be sufficient to produce successful outcomes for youth in expensive, restrictive out-of-home placements. Modifications in case loads, training, and supervision may be necessary, but not sufficient, conditions for achieving successful reunification outcomes. This project identified five major service system barriers that impede reunification. 


\section{Barriers to Reunification}

Petr \& Entriken

The fact that the system of care for youth in our project was so antithetical to reunification may indicate that reunification is controversial and not readily endorsed by many professionals and the general public. Citizens and professionals may prefer that troubled children be placed out of the community, where they are someone else's responsibility. People may believe that placement of a child signifies that the child or family is so troubled that reintegration is not possible. This attitude may prevail, especially with youth like those represented in this project-teenagers who have been in the system a long time or who have committed crimes. Perhaps society does not want to invest time and money in kids who it feels are too tough or too old to impact.

By contrast, the opposing point of view holds that excessive time and money is already being spent on these children, with little or no documentation of results. This viewpoint recognizes that most children eventually return to their families and communities and have a greater chance to succeed if active reunification efforts are undertaken.

Perhaps the situation has been polarized by the system's emphasis on the concept of reintegration rather than the broader concept of reunification. Reintegration is not always appropriate for children, but reunification goals almost always are. The goals for all children in custody are to live productively in their community with the maximum possible emotional connection with their families. Focusing on reunification rather than reintegration may be one way to combat the negative attitudes discussed above and thus create an attitudinal consensus that firmly establishes reunification as the driving force of service delivery.

\section{REFERENCES}

Allen, M. (1992, Fall). Redefining family reunification. In The prevention report (pp. 5-7). Iowa City, IA: National Resource Center on Family-Based Services.

Annie E. Casey Foundation. (1992). The Annie E. Casey Foundation 1992 annual report. Greenwich, CT: Author.

Borgman, R. (1985). The influence of family visiting upon boys' behavior in a juvenile correctional institution. Child Welfare, 64, 629-638.

Bruner, C. (1989). State innovations in children and family service collaboration and financing. In C. Roning (Ed.), Family policy: Recommendations for state action (pp. 163-171). Denver, CO: National Conference of State Legislators.

Deiker, T. (1986). How to ensure that the money follows the patient: A strategy for funding community services. Hospital and Community Psychiatry, $37,256-260$.

Diorio, W. (1992). Parental perceptions of the authority of public child welfare caseworkers. Families in Society, 73, 222-235.

Fein, E., \& Staff, I. (1993). Last best change: Findings from a reunification services program. Child Welfare, $72,25-40$.

Frankel, H. (1988). Family centered, home based services in child protection: A review of the research. Social Services Review, 62, 137-157.

Friesen, B. J., \& Koroloff, N. (1990). Family centered services: Implications for mental health administration and research. Journal of Mental Health Ad- ministration, 17, 13-25.

George, R. M. (1990). The reunification process in substitute care. Social Service Review, 64, 422-457.

Gordon, D. A., Arbuthnot, J., Gustafson, K. E., \& McGreen, P. (1988). Home-based behavioral-systems family therapy with disadvantaged juvenile delinquents. American Joumal of Family Therapy, $16,243-255$.

Hess, P. M., \& Folaron, G. (1991). Ambivalences: A challenge to permanency for children. Child Welfare, 70, 403-424.

Jennings, M. A., \& McDonald, T. P. (1993). Assessing the impact of citizen review boards. Lawrence, KS: School of Social Welfare, University of Kansas.

Kagan, R., Reid, W. J., Roberts, S. E., \& SilvermanPollow, J. (1987). Engaging families of courtmandated youths in an alternative to institutional placement. Child Welfare, 66, 365-376.

Krieger, R., Maluccio, A., \& Pine, B. (1991). Teaching family reunification: A sourcebook. West Hartford, CT: Center for the Study of Child Welfare, University of Connecticut.

Lahti, J. (1982). A follow-up study of foster children in permanent placements. Social Service Review, $56,556-571$

McDonald, T., \& Marks, J. (1991). A review of risk factors assessed in child protective services. Social Service Review, 65, 112-132.

Petr, C. G., \& Barney, D. (1993). Reasonable efforts for children with disabilities: The parent perspective. Social Work, 35, 247-255. 
Families in Society

November 1995

Petr, C. G., \& Entriken, C. (1993). Sedguick County Pilot Reunification Project. Topeka, KS: Corporation for Change.

Petr, C. G., \& Spano, R. (1990). Evolution of social services for children with emotional disorders. Social Work, 35, 228-234.

Poertner, J., \& Ronnau, J. (1992). A strengths approach to children with emotional disabilities. In D. Saleebey (Ed.), A strengths perspective in social work practice (pp. 111-121). New York: Longman.

Rapp, C. A., \& Moore, T. (1993). The Kansas mental health reform act: Legislation that works. Lawrence, KS: Schonl of Social Welfare, University of Kansas.

Schwartz, I. M. (1992). Juvenile justice and public policy: Toward a national agenda. New York: Lexington Books.

Tarico, V. S., Low, B. P., Trupin, E., \& ForsythStephens, A. (1989). Children's mental health ser- vices: A parent perspective. Community Mental Health Journal, 25, 313-326.

Turnbull, A., \& Turnbull, H. (Eds.). (1990). Families, professionals and exceptionality: A special partnership (2nd ed.). Columbus, OH: Charles H. Merrill.

Turnbull, H., \& Turnbull, A. (1985). Parents speak out, then and now. Columbus, $\mathrm{OH}$ : Charles $\mathrm{H}$. Merrill.

Walton, E., Fraser, M. W., Lewis, R. E., Pecora, P. J., \& Walton, W. K. (1993). In-home family-focused reunification: An experimental study. Child Welfare, $72,473-487$

Wells, K., \& Biegel, D. E. (Eds.). (1991). Family preservation services: Research and evaluation. Newbury Park, CA: Sage Publications.

Whitaker, J. K., Kinney, J., Tracy, E. M., \& Booth, C. (1990). Reaching high-risk families: Intensive family preservation in human services. New York: Aldine de Gruyter.
To earn $3 \mathrm{CEU}$ for reading this article:

- Complete the test on the following pages or on a photocopy of it.

- Write one of the following: (1) a critical review of the article, (2) a detailed explanation of how you will be able to use the information in the article in your professional activity, or (3) a reflection on the relevance of the content of the article to human services generally. Your essay must be at least 300 words but no more than 500 words long and must be typed or word processed.

- Send the completed test, essay, and a $\$ 12.50$ check payable to Family Service America, Inc., to

International Training Center

Family Service America, Inc.

11700 West Lake Park Drive

Milwaukee, WI 53224

The International Training Center will notify you as to whether you have satisfactorily met the requirements for $3 \mathrm{CEU}$ for this article. The center will send notification of your earned credits in quantities of .6 CEU to the American Council on Education's National Registry for Training Programs. The center will hold any completed test-essay unit until or unless it can be paired with another for submission of your .6 CEU to the National Registry.

An editor from Families in Society is available to answer your questions or otherwise facilitate your completion of the test or essay. Call 414-359. 1040 for help.

For a description and rationale of the Families in Society Continuing Education Program, send a stamped, self-addressed $\# 10$ (business-size) envelope to:

Families in Society CEU Program 11700 West Lake Park Drive Milwaukee, WI 53224

\section{CEU Test No. 56}

1. What did child-welfare programming and research subsequent to P.L. $96-272$ emphasize?

What does P.L. 96-272 emphasize in addition?

2. During placement, new persons and systems become involved with the child, including and
3. Reunification efforts are constrained by , and contexts.

4. The following could help policymakers design more effective reunification initiatives: clear and a of the , and

that inhibit and impede reunification efforts.

5. The premise of the project discussed in this article was that successful reunification efforts at a direct-practice level require (1) 
(2)

(3)

6. Reintegration refers to the physical reintegration of children

reunification is a

that includes

term

7. as one component. and are important reunification goals. Thus, even when physical reintegration is not the goal, the child can still be returned to , and the child and family can attain some measure of emotional

8. The sampling pool in this study included

children) and or or or

9. Case management intervention in this project emphasized the following:

1.

2.

3.

4.

10. The two reunification case managers were charged with mobilizing an whose programs and policies were to

11. In 14 of the 20 cases studies, so severe was the inattention to seven children were abruptly before the case manager could

12. Geographic distance made it much more difficult for the local foster-care worker to and to of the case plan.

13. Many staff in youth correctional facilities stereotyped parents as and and refused to even after case managers had forged good working relationships
14. All 20 children met the state department of mental health's definition of

were able to access yet few of the youth

15. When families were approached in a they could be engaged in a way,

16. What may follow from being over cautious about reintegration?

17. What two consequences may follow from taking too great a risk with reintegration?

1.

2.

18. Limiting placement to a child's neighborhood and community enhances the child's

the community's and and underscores in the care of children.

19. To implement family-centered practice, what two strategies need to be initiated?

1.

2.

20. training in reunification should be required of all workers.

21. States would serve their interests by reviewing the , and of their juvenile-justice programs, with particular attention to programs that successfully emphasize the role of and $\quad$ in the of youth and __ of the community.

22. ate for children, but is not always approprialmost always are. 